\title{
Risk Assessment of Heavy Metals Pollution in Farmland Soil Around a Mine
}

\author{
Zhendi Fan ${ }^{1, a}$, Jingying Chen ${ }^{1, b}$ and Bai Gao ${ }^{2, c}$ \\ ${ }^{1}$ State Key Laboratory Breeding Base of Nuclear Resources and Environment, East China Institute \\ of Technology,Nanchang,330013,Jiangxi,China \\ ${ }^{2}$ School of Water Resources \& Environmental Engineering, East China University of Technology, \\ Nanchang 330013, China \\ a2832085867@qq.com, bjy006@ecit.cn, cgaobai@ecit.cn
}

Keywords: mine soil; heavy metals; risk assessment

\begin{abstract}
The exploitation of mine has made a great contribution to the social development. But it has caused a series of environmental pollution problems, especially the heavy metals pollution in the soil. In this paper, we assessed the ideas with a uranium repository surrounding farmland as the research object by using geoaccumulation index and potential ecological risk index. According to geoaccumulation index of each site, it is shows that Mn belongs to no pollution levels, heavy metal $\mathrm{Cr}, \mathrm{Ni}$, zinc and $\mathrm{Pb}$ belong to light pollution levels; According to the potential ecological risk index, it works out that the area of farmland is mainly polluted by heavy metal $\mathrm{Ni}$ and $\mathrm{Cu}$, and heavy metal pollution is more serious in soil near the sewage discharge channels.
\end{abstract}

\section{Introduction}

Soil is the basis for agricultural production and it is an integral part of human existence. The soil is the most that cannot be ignored among the various environmental pollution. Meanwhile, excessive accumulation of certain heavy metals can lead soil's microbial biomass decrease, so that the soil fertility and loose performance become low. In addition, the growth of some crops is inhibited by the adsorption and accumulation of plants, and most of the heavy metals in soil owns concealment and long-term nature. Therefore, the study of soil heavy metals is significant and it can provide a reference for the research of heavy metal pollution in the farmland around the mine ${ }^{[1]}$.

\section{Assessment Method of Soil Heavy Metals Pollution}

\section{Assessment according to geoaccumulation index.}

A common criterion, which was originally defined by Muller (1979) to deter-mine metals contamination in sediments ${ }^{[2-3]}$, is the geoaccumulation index (Igeo) to evaluate the heavy metal pollution in sediments, by comparing current concentrations with preindustrial levels and can be calculated by the following equation:

$$
\mathrm{I}_{\text {geo }}=\log _{2}\left[C_{i} /\left(1.5 * B_{i}\right)\right]
$$

It showed that $\mathrm{Ci}$ is the measured concentration of the examined metal (i) in the sediment, $\mathrm{Bi}$ is the geochemical back-ground concentration of the metal (i), and factor 1.5 is the background matrix correction factor. 
Table 1 Muller's classification for the geoaccumulation index

\begin{tabular}{ccl}
\hline & Igeo class & Quality of sediment \\
\hline$\leq 0$ & 0 & Unpolluted \\
$0-1$ & 1 & From unpolluted to moderately polluted \\
$1-2$ & 2 & Moderately polluted \\
$2-3$ & 3 & From moderately to strongly polluted \\
$3-4$ & 4 & Strongly polluted \\
$4-5$ & 5 & From strongly to extremely polluted \\
$>5$ & 6 & Extremely polluted \\
\hline
\end{tabular}

Assessment according to potential ecological risk index.

$\mathrm{RI}$ is introduced to assess the ecological risk degree of heavy metals in soil or sediments, which was originally proposed by HAKANSON and widely used ${ }^{[4-5]}$. The value of RI can be calculated by the following formulas:

$$
\begin{aligned}
& \mathrm{Q}_{\mathrm{i}}=C_{i} / B_{i} \\
& \mathrm{E}_{\mathrm{i}}=T_{i} * Q_{i} \\
& \mathbf{R I}=\sum_{i=1}^{\mathrm{n}} \boldsymbol{E}_{i}
\end{aligned}
$$

Where RI is the sum of potential risk of individual heavy metal; Ei is the potential risk of individual heavy metal; $\mathrm{Ti}$ is the toxic-response factor for a given heavy Metal; $\mathrm{Q} i$ is the contamination coefficient; $\mathrm{Ci}$ is the present concentration of heavy metals in sediments. $\mathrm{Bi}$ is the pre-industrial record of heavy metal concentration in sediments.

Table 2 Indices and grades of potential ecological metals contamination

\begin{tabular}{ccc}
\hline $\mathrm{E}_{\mathrm{i}}$ & $\mathrm{RI}$ & $\begin{array}{c}\text { Grade of potential Ecological risk } \\
\text { of environment }\end{array}$ \\
\hline$<40$ & $<150$ & Low risk \\
$40 \leq \mathrm{E}_{\mathrm{1}}<80$ & $150 \leq \mathrm{RI}<300$ & Moderate risk \\
$80 \leq \mathrm{E}_{1}<160$ & $300 \leq \mathrm{RI}<600$ & Considerable risk \\
$160 \leq \mathrm{E}_{1}<320$ & $600 \leq \mathrm{RI}<1200$ & High risk \\
$320 \leq$ & $1200 \leq$ & Very high risk \\
\hline
\end{tabular}

\section{Experimental Approach}

We choosed farmland soil around a mine tailings pond as the research object. The research land was uneven, and the area of land was large. So we adopted snake type location method for sampling. We Collected surface soil with plastic bags then put the samples back to the laboratory to processing and analysising test. All sites were located in the downstream of the tailings pond within $1000 \mathrm{~m}$ of the research land. The soil samples was put into oven in laboratory to dry. Set the oven temperature to 70 , and dry $72 \mathrm{~h}$. The samples was grinded after drying, and poured into different aperture sieve to sift. The samples were analysised with X fluorescence spectrum analyzer.

\section{Results and Discussion}

The surface soil of 11 sample Sites was analysised in the farmland. It was applied Grade II standard of China environmental quality standard for soil (GB15618 -1995).and used soil background values in jiangxi province to assesse ${ }^{[6]}$. 


\section{Assessment of geoaccumulation index.}

According to geoaccumulation index of each Site in Table 3,for the whole reach land soil average pollution levels, $\mathrm{Mn}$ belonged to no pollution levels,heavy metal $\mathrm{Cr}$, $\mathrm{Ni}$, zinc and $\mathrm{Pb}$ belonged to light pollution levels, $\mathrm{Cu}$ belonged to the moderate pollution levels.According to geoaccumulation index of each site, all sites belong to light pollution levels, the level of soil pollution was relatively higharound Site 11.

Table 3 The geoaccumulation index of each sample site of surface soil in farmland

\begin{tabular}{lccccccc}
\hline Sample & $\mathrm{Cr}$ & $\mathrm{Mn}$ & $\mathrm{Ni}$ & $\mathrm{Cu}$ & $\mathrm{Zn}$ & $\mathrm{Pb}$ & Average \\
\hline Site 1 & 0.9 & -0.5 & 0.9 & 0.9 & 0.5 & -0.1 & 0.4 \\
Site 3 & 1.0 & -1.3 & 0.8 & 0.8 & 0.2 & 0.1 & 0.3 \\
Site 4 & 1.0 & -0.5 & 0.9 & 1.0 & 0.4 & 0.1 & 0.5 \\
Site 5 & 1.0 & -1.3 & 0.9 & 0.8 & 0.3 & 0.2 & 0.3 \\
Site 6 & 1.0 & -0.7 & 0.8 & 0.3 & 0.3 & 0.3 & 0.4 \\
Site 7 & 0.9 & -0.9 & 1.0 & 1.0 & 0.5 & 0.0 & 0.4 \\
Site 8 & 1.0 & -0.3 & 0.9 & 1.0 & 0.4 & 0.1 & 0.5 \\
Site 9 & 0.8 & -1.3 & 0.7 & 1.1 & 0.4 & 0.1 & 0.3 \\
Site 10 & 0.8 & -0.5 & 1.1 & 1.3 & 0.4 & 0.5 & 0.6 \\
Site 11 & 0.9 & -0.2 & 1.1 & 1.3 & 0.5 & 0.4 & 0.7 \\
Site 13 & 0.8 & -0.7 & 0.9 & 1.1 & 0.4 & 0.2 & 0.4 \\
Average & 0.9 & -0.7 & 0.9 & 1.0 & 0.4 & 0.2 & \\
\hline
\end{tabular}

\section{Assessment of potential ecological risk index.}

According to Table 4, The level of potential ecological risk of heavy metals pecking order was: $\mathrm{Cu}>\mathrm{Ni}>\mathrm{Pb}>\mathrm{Cr}>$ zinc $>\mathrm{Mn}$, this showed that heavy metal pollutions of soil were focused on $\mathrm{Cu}$ and $\mathrm{Ni}$. In addition, according to the potential ecological risk index, heavy metals pollution was worse in soil around Site 10 and Site 11, while oil heavy metal pollution level was the lowest around Site 3.

Based on single factor index number technique,integrated pollution index,geoaccumulation index and potential ecological risk index,the results of assessment were similar. $\mathrm{Ni}$ and $\mathrm{Cu}$ pollution were more serious, then the $\mathrm{Cr}$, zinc and $\mathrm{Pb}$ pollution are a lesser degree.Mn pollution was the lowest levels.

Table 4 The potential ecological risk index of each sample site of surface soil in farmland

\begin{tabular}{lccccccc} 
Sample & \multicolumn{1}{c}{ Cr } & Mn & $\mathrm{N}_{\mathbf{1}}$ & $\mathrm{Cu}$ & $\mathrm{Zn}$ & $\mathrm{Pb}$ & Integration \\
\hline Site 1 & 5.4 & 1.1 & 14.3 & 14.5 & 2.2 & 7.0 & 44.4 \\
Site 3 & 6.1 & 0.6 & 13.1 & 13.8 & 1.8 & 7.9 & 42.7 \\
Site 4 & 6.1 & 1.1 & 13.9 & 15.0 & 2.0 & 7.9 & 46.0 \\
Site 5 & 6.1 & 0.6 & 14.2 & 13.3 & 1.9 & 8.6 & 44.8 \\
Site 6 & 5.9 & 0.9 & 13.6 & 12.9 & 1.8 & 9.0 & 44.0 \\
Site 7 & 5.5 & 0.8 & 15.4 & 15.0 & 2.1 & 7.5 & 46.3 \\
Site 8 & 5.9 & 1.2 & 13.6 & 14.9 & 2.0 & 8.0 & 45.7 \\
Site 9 & 5.2 & 0.6 & 12.1 & 16.5 & 2.0 & 8.2 & 44.7 \\
Site 10 & 5.4 & 1.1 & 15.8 & 18.2 & 2.0 & 10.3 & 52.7 \\
Site 11 & 5.7 & 1.3 & 15.7 & 18.5 & 2.1 & 9.6 & 52.8 \\
Site 13 & 5.1 & 0.9 & 13.6 & 16.0 & 1.9 & 8.6 & 46.2 \\
Average & 5.7 & 0.8 & 14.1 & 15.3 & 2.0 & 8.4 & 46.4 \\
\hline
\end{tabular}




\section{Conclusion}

Based on index of geo-accumulation and the potential ecological risk, the soil around the tailings pond seriously is polluted by $\mathrm{Cu}$ and $\mathrm{Ni}$. Analysising from the potential ecological risk index, that soil heavy metal pollution is higher around Site 10 and Site 11,soil heavy metal pollution level is the lowest around Site 3.

\section{Acknowledgments}

This work was supported by the National Natural Science Foundation of China (21407023, 41162007, 41362011).

\section{References}

[1] Rong,Y.J..Use X-ray fluorescence spectrometry measure 24 kinds of main, and trace elements in soil samples [D].Jilin University, 2012.

[2] Müller,G..Index of geoaccumulation in sediments of River[J]. Geo. Journal, 1969, 2:108-118.

[3] Liu,Y.,Qiu,L.L.,Ji,J.C.Soil heavy metal pollution and it’s potential ecological risk assessment[J]. Acta Scientiae Circumstantiae,2011,31(6): 1285-1293.

[4] Fan,S.X.,Gan,T.T.,Li.M.J..Progress of Assessment Methods of Heavy Metal Pollution in Soil

[J], Chinese Agricultural Science Bulletin,2010,26(17):310-315.

[5] Hakanson L.An ecological risk index for aquaticpollution control: a sediment logical approach[J]. Water Res, 1980, 14:975-1001.

[6] Peng,K.S..Jiangxi Ecological (Book Three)[M]. Nanchang;Jiangxi People's Publishing House,2007 